\title{
On the linear diophantine problem of Frobenius in three variables
}

\author{
Ryozo Morikawa \\ (Received June 16, 1997)
}

\section{Introduction}

Let $a_{1}, \ldots, a_{k}$ be a set of positive integers with $\operatorname{gcd}\left(a_{1}, \ldots, a_{k}\right)=1$.

We say that an integer $n$ is $\mathbf{N}$-dependent on $\left\{a_{1}, \ldots, a_{k}\right\}$ if there exist positive integers $x_{i} \quad(1 \leqq i \leqq k)$ such that

(1) $\mathrm{n}=\mathrm{x}_{1} \mathrm{a}_{1}+\cdots \cdots+\mathrm{x}_{\mathrm{k}} \mathrm{a}_{\mathrm{k}}$.

The problem of Frobenius consists in determining the largest integer which is not $\mathbf{N}$-dependent on $\left\{a_{1}, \ldots, a_{k}\right\}$. We denote the number by $F\left(a_{1}, \ldots, a_{k}\right)$. We treat in this paper the problem for $k=3$. It must be noted the result obtained in this paper gives a prototype of a general theory for the problem of Frobenius. But even in case $\mathrm{k}=4$, many new phenomena are observed, and we need further investigations. The case $\mathrm{k}=4$ will be treated elsewhere.

The starting point of our investigation is that of Johnson [4] and of BrauerShockley [1]. And we refer to the paper of Davison [2] which has a close relation with our result. The paper gives also a survey of the current investigations. For the general background of the problem, we refer to Erdös-Graham [3] pp. 85-86.

Now we explain the contents of this paper. Let $\mathbf{N}$ and $\mathbf{Z}$ mean as usual. And $\left(a_{1}, \ldots, a_{k}\right)$ means the gcd $\left(a_{1}, \ldots, a_{k}\right)$. We take three positive integers $a, b$ and $\mathrm{c}$ with $(\mathrm{a}, \mathrm{b}, \mathrm{c})=1$. Let $\mathrm{F}(\mathrm{a}, \mathrm{b}, \mathrm{c})$ be the Frobenius number, which will be noted in some places simply by $\mathrm{F}$.

In $\$ 2$, we reconstruct the discussion of Brauer-Shockley [1] from a somewhat different standpoint. We first ascertain Theorem 1 which is the main result of 
[1]. It asserts, in brief, $F=\operatorname{Max}\left(F_{1}, F_{2}\right)$ where $F_{i}$ 's are determined by $\{a$, $\mathrm{b}, \mathrm{c}$ ). ( For $\mathrm{k}=4$, if the situation is normal, we obtain $\mathrm{F}$ by comparing six numbers $F_{\mathrm{i}}(1 \leqq i \leqq 6)$. Note that $6=(4-1)$ ! and $2=(3-1)$ !. But as noted above, new phenomena appear even in case $\mathrm{k}=4$, and the cardinality 6 considerably varies according to the proportions of $a_{i}(1 \leqq i \leqq 4)$.)

In $\S 3$, Theorem 2 gives formulas which represents $\mathrm{a}, \mathrm{b}, \mathrm{c}$ and $\mathrm{F}$ by using six positive integers $b_{i}, c_{i}(1 \leqq i \leqq 3)$. ( Conversely starting from $\{a, b, c\}$, we obtain $b_{i}, c_{i}(1 \leqq i \leqq 3)$ by aid of the algorithm given by Davison [2].)

In 84 , we apply above results to study $\mathrm{F} /(\mathrm{abc})^{1 / 2}=\theta(\mathrm{a}, \mathrm{b}, \mathrm{c})$. We express $\theta$ as a function of three parameters (p, q, r) with $0<\mathrm{p}<1,0<\mathrm{q}<1$ and $0<\mathrm{r}<1$. We obtain a precise knowledge about the value of $\theta$ including the inequality $\theta>\sqrt{3}$. (This inequality is given by Davison [2].)

In 85 , we continue the study by drawing curves $\theta$ (p, q, r) $=$ const. Those Figures show that $\theta$ remains rather small as anticipated in [2]. ( But we could not give a proof of the conjectures given in $\$ 4$ of [2].)

\section{2. $F=\operatorname{Max}\left(F_{1}, F_{2}\right)$}

Let $\mathrm{a}, \mathrm{b}, \mathrm{c} \in \mathbf{N}$ with $(\mathrm{a}, \mathrm{b}, \mathrm{c})=1$. We start with two usuful Lemmas which are given by Johnson [4].

Lemma 1 (Johnson [4] Theorem 1). The Frobenius number $\mathrm{F}(\mathrm{a}, \mathrm{b}, \mathrm{c})$ is $\mathbf{N}$ dependent on any of $\{\mathrm{b}, \mathrm{c}\},\{\mathrm{c}, \mathrm{a}\}$ and $\{\mathrm{a}, \mathrm{b}\}$.

Proof. Since $\mathrm{F}+\mathrm{a}$ is $\mathbf{N}$-dependent on $\{\mathrm{a}, \mathrm{b}, \mathrm{c}\}$, we have $\mathrm{F}+\mathrm{a}=\mathrm{xa}+$ $y b+z c$ with $(x, y, z) \in N^{3}$. If $x>1$, then $F=(x-1) a+y b+z c$. It contradicts the definition of $F$. Thus $x=1$. Namely we have $F=y b+z c$. The same reasoning works for $\{c, a\}$ and $\{a, b\}$.

Lemma 2 ( Johnson [4] Theorem 2). Let $(b, c)=d>1$. Then we have $F$ $(\mathrm{a}, \mathrm{b}, \mathrm{c})=\mathrm{d} F(\mathrm{a}, \mathrm{b} / \mathrm{d}, \mathrm{c} / \mathrm{d})$. 
Proof. We put $\mathrm{b}=\mathrm{b}^{\prime} \mathrm{d}$ and $\mathrm{c}=\mathrm{c}$ d. By Lemma 1, we put $\mathrm{F}=\mathrm{yb}+\mathrm{zc}$ with $(y, z) \in N^{2}$. Thus $F=d\left(y b^{\prime}+z c^{\prime}\right)$. We put $F^{\prime}=F / d$, and show the relation $F^{\prime}=F\left(a, b^{\prime}, c^{\prime}\right)$. First we ascertain that $F^{\prime}$ is not $\mathbf{N}$-dependent on $\left\{a, b^{\prime}, c^{\prime}\right.$ \}. If $\mathrm{F}^{\prime}=\mathrm{ua}+\mathrm{vb}+\mathrm{wc}$ with $(\mathrm{u}, \mathrm{v}, \mathrm{w}) \in \mathrm{N}^{3}$, then $\mathrm{F}=\mathrm{dF}=\mathrm{uda}+\mathrm{vb}+$ wc. It contradicts the definition of $\mathrm{F}$. Next we take $\mathrm{n} \in \mathbf{N}$ with $\mathrm{n}>\mathrm{F}$. Here nd $>$ F. Thus we have $n d=x a+y b+z c$ with $(x, y, z) \in N^{3}$. And the relation $\mathrm{d} \mid \mathrm{b}$ and $\mathrm{d} \mid \mathrm{c}$ implies $\mathrm{d} \mid \mathrm{x}$. Therefore we obtain the relation $\mathrm{n}=$ $(x / d) a+y b^{\prime}+z c^{\prime}$. These two properties assert $F^{\prime}=F\left(a, b^{\prime}, c^{\prime}\right)$.

As is well known, if $a$ is $\mathbf{N}$-dependent on $\{b, c\}$, we have $F(a, b, c)=a+$ bc. By virtue of this fact and of Lemma 2, we may hereafter impose the following condition on $\{a, b, c\}$.

(\#) a, b, c are coprime positive integers and none of a, b, c does not $\mathbf{N}$-dependent on the other two members.

Note that the second condition of (\#) implies

(*) a, b, c $\geqq 2$.

Our aim of this $\S$ is to characterize $F$ among the numbers which satisfy the property stated in Lemma 1 . As noted in $\S 1$, the discussion of this $\S$ owes much to Brauer-Shockley. We introduce the following terminology and notation:

We call a form of the following type (2) is a 0 -form.

(2) $\mathrm{xa}+\mathrm{yb}+\mathrm{zc}=0$ with $(\mathrm{x}, \mathrm{y}, \mathrm{z}) \in \mathbf{Z}^{3}$.

We consider the set $(x, y, z)$ of (2) as a vector and denote it as $\mathbf{w}=(x, y, z)$. We frequently call (2) as a 0 -form $(x, y, z)$ or a 0 -form w. We put (3) $\mathrm{W}=\left\{(\mathrm{x}, \mathrm{y}, \mathrm{z}) \in \mathrm{Z}^{3}: \mathrm{ax}+\mathrm{by}+\mathrm{cz}=0\right\}$.

Lemma 3. We take $\{\mathrm{a}, \mathrm{b}, \mathrm{c}\}$ with (\#) and $\mathrm{W}$ as (3). Then $\mathrm{W}$ makes a Zmodule of rank 2. As a base system of $\mathrm{W}$, we can choose $\mathbf{v}_{\mathbf{1}}=(1,-\mathrm{v}, \mathrm{W})$ and $\mathbf{v}_{2}=(0, \mathrm{c},-\mathrm{b})$ which satisfy the following (4).

(4) $0<\mathrm{v}<\mathrm{c}$ and $0<\mathrm{w}<\mathrm{b}$. 
Conversely the vector system $\left\{\mathbf{v}_{1}, \mathbf{v}_{\mathbf{2}}\right\}$ is determined uniquely by (4).

Proof. The first assertion of Lemma is obvious. And (b, c) $=1$ implies the third assertion. Thus we consider the second assertion. Since $(a, b, c)=1$, there exist two numbers $\mathrm{v}, \mathrm{w} \in \mathbf{Z}$ for which $\mathrm{a}=\mathrm{bv}-\mathrm{cw}$. By translating $\mathrm{v}$ modulo $\mathrm{c}$, we may assume $0<\mathrm{v}<\mathrm{c} .\left((\mathrm{a}, \mathrm{c})=1\right.$ and $(*)$ implies $\mathrm{v}^{\prime} \neq 0$. $)$

Now $\mathrm{w}<0$ means a to be $\mathbf{N}$-dependent on $\{\mathrm{b}, \mathrm{c}\}$, and $(\mathrm{a}, \mathrm{b})=1$ and $(*)$ implies $\mathrm{w} \neq 0$. Thus we have $\mathrm{w} \in \mathbf{N}$. And $\mathrm{a}>0$ and $0<\mathrm{v}<\mathrm{c}$ imply $\mathrm{w}<$ b.

Now we introduce the following two sets of 0 -forms.

$$
\begin{aligned}
& B=\{(x,-y, z): x a-y b+z c=0 \text { and } x, y, z \in N\} \\
& C=\{(x, y,-z): x a+y b-z c=0 \text { and } x, y, z \in N\}
\end{aligned}
$$

Lemma 4. (i) We take $\mathbf{b}=\left(\mathrm{b}_{1},-\mathrm{b}_{2}, \mathrm{~b}_{3}\right) \in \mathrm{B}$ and $\mathbf{c}=\left(\mathrm{c}_{1}, \mathrm{c}_{2},-\mathrm{c}_{3}\right)$ $\in \mathrm{C}$ for which

$$
\begin{aligned}
& \mathrm{b}_{2}=\operatorname{Min} \mathrm{y} \text { among }(\mathrm{x},-\mathrm{y}, \mathrm{z}) \in \mathrm{B}, \\
& \mathrm{c}_{3}=\operatorname{Min} \mathrm{z} \text { among }(\mathrm{x}, \mathrm{y},-\mathrm{z}) \in \mathrm{C} .
\end{aligned}
$$

Then $\mathbf{b}$ and $\mathbf{c}$ are determined uniquely by above conditions. And we have

(6) $2 \leqq \mathrm{~b}_{2}<\operatorname{Min}(\mathrm{a}, \mathrm{c})$ and $2 \leqq \mathrm{c}_{3}<\operatorname{Min}(\mathrm{a}, \mathrm{b})$.

(ii) $\{\mathbf{b}, \mathbf{c}\}$ makes a basis system of $\mathrm{W}$.

(iii) We put $\mathbf{a}=\mathbf{b}+\mathbf{c}$. Let $\mathbf{a}=\left(\mathrm{a}_{1},-\mathrm{a}_{2},-\mathrm{a}_{3}\right)$. Then $\mathrm{a}_{\mathrm{i}} \in \mathbf{N}$.

(iv) The 0 -form $\mathbf{a}$ is characterized by the following property. $\mathrm{a}_{1}=\operatorname{Min} \mathrm{x}$ for which $\mathrm{xa}-\mathrm{yb}-\mathrm{zc}=0$ and $(\mathrm{x}, \mathrm{y}, \mathrm{z}) \in \mathbf{N}^{3}$.

Proof. First we treat (i) for $\mathbf{b}$. The number $b_{2}$ is characterized as the minimum value for which $b_{2} b$ becomes $\mathbf{N}$-dependent on $\{a, c\}$. By (\#), we see $\mathrm{b}_{2} \geqq 2$. And (4) implies $\mathrm{b}_{2} \leqq \mathrm{v}<\mathrm{c}$. Now interchanging $\mathrm{c}$ and $\mathrm{a}$, we obtain $b_{2}<a$. Now assume that $b_{2} b$ allows the following two expressions.

$$
\begin{aligned}
b_{2} b & =b_{1} a+b_{3} c \text { with } \quad b_{1}, b_{3} \in \mathbf{N} \\
& =\widehat{b_{1}} a+\widehat{b_{3}} c \text { with } \quad \widehat{b_{1}}, \widehat{b_{3}} \in \mathbf{N}
\end{aligned}
$$


Since $(a, c)=1, b_{1}>c$ or $\hat{b}_{1}>c$. Let $b_{1}>c$. By the same reasoning used in Lemma 3, we have

(8) $\mathrm{b}=\mathrm{ta}-\mathrm{uc}$ with $0<\mathrm{t}<\mathrm{c}, 0<\mathrm{u}<\mathrm{a}$ and $\mathrm{t}, \mathrm{u}$ in $\mathbf{N}$.

By (7) and (8), we obtain the following relation with coefficients in $\mathbf{N}$ :

$$
\left(b_{2}-1\right) b=\left(b_{1}-t\right) a+\left(b_{3}+u\right) c .
$$

It contradicts the minimality of $b_{2}$. Thus we obtain (i) for $\mathbf{b}$. The same reasoning works for c.

(Proof of (ii)) We study properties of 0 -form $\mathbf{w}$ by expressing it as $\mathbf{w}=$ $\mathrm{gv}_{1}+\mathrm{h} \mathbf{v}_{2}$ with $(\mathrm{g}, \mathrm{h}) \in \mathbf{Z}^{2}$. We define $\mathrm{f}$ by $\mathrm{f}(\mathbf{w})=(\mathrm{g}, \mathrm{h})$. Note that

(9) $g \mathbf{v}_{1}+h \mathbf{v}_{2}=(\mathrm{g},-\mathrm{gv}+\mathrm{ch}, \mathrm{gw}-\mathrm{bh})$.

And we use Figure 1 as an aid to the discussion. In the Figure, $Q=(b, w)$, $R=(c, v), P_{1}=f(\mathbf{b})=\left(g_{1}, h_{1}\right), P_{2}=f(\mathbf{c})=\left(g_{2}, h_{2}\right)$ and $P_{3}=f(a)$ $=\left(\mathrm{g}_{3}, \mathrm{~h}_{3}\right)$.

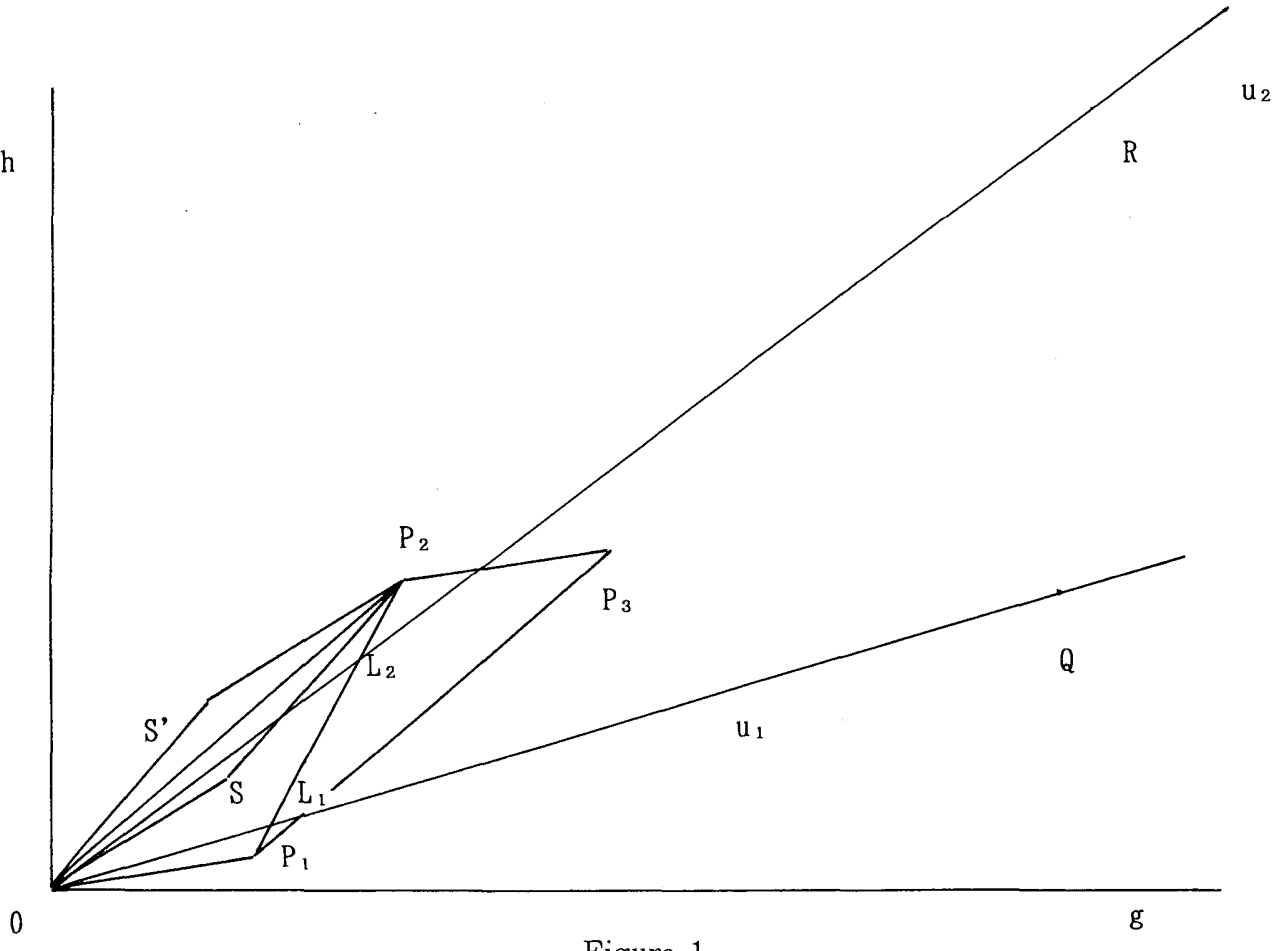

Figure 1.

For the explanation of Figure 1, we note the following two facts.

(a) By the definition of $\mathbf{b}$ and $\mathbf{c}$, we have $\mathrm{h}_{1} / \mathrm{g}_{1}<\mathrm{w} / \mathrm{b}<\mathrm{v} / \mathrm{c}<\mathrm{h}_{2} / \mathrm{g}_{2}$. 
(b) $\mathbf{b}$ is characterized by the property that the area of $\triangle \mathrm{ORP}_{1}\left(=\mathrm{b}_{2} / 2\right)$ attains the minimum value among $\triangle \mathrm{ORP}$ with $\mathrm{P} \in \mathrm{f}(\mathrm{B})$. (We denote by $\triangle \mathrm{ABC}$ the area of triangle $\mathrm{ABC}$.)

To ascertain (ii), we show that the parallelotope $\mathrm{OP}_{1} \mathrm{P}_{3} \mathrm{P}_{2}$ contains no latice points except the four vertices of it. Assume the existence of another lattice point $S=\left(g_{0}, h_{0}\right)$. By virtue of symmetry of a parallelotope, we may assume $S \in \triangle O P_{1} P_{2}$. Furthermore by the minimality of $\mathbf{b}$ and $\mathbf{c}$, we may assume $\mathrm{S} \in \triangle \mathrm{OL}_{1} \mathrm{~L}_{2}$ where $\mathrm{L}_{1}$ and $\mathrm{L}_{2}$ are the intersetions of $\overline{\mathrm{P}_{1} \mathrm{P}_{2}}$ and two lines $\mathrm{u}_{1}$ and $\mathrm{u}_{2}$ respectively.

Now we separate into two cases.

(In case $\mathrm{g}_{2} \geqq \mathrm{~g}_{1}$ ) We make the parallelotope $\mathrm{OSP}_{2} \mathrm{~S}^{\prime}$ as in Figure 1. Let $\mathrm{S}^{\prime}=\left(\mathrm{g}^{\prime}, \mathrm{h}^{\prime}\right)$. Since $\overline{\mathrm{OS}}$ is contained in $\triangle \mathrm{OL}_{1} \mathrm{~L}_{2}$, we have (10) $\triangle \mathrm{OQS}^{\prime} \leqq \triangle \mathrm{OQP}_{2}(<\mathrm{b} / 2)$.

Note that except the case $\mathrm{g}_{1}=\mathrm{g}_{2}=\mathrm{g}_{0}, \mathrm{~g}^{\prime}=\mathrm{g}_{2}-\mathrm{g}_{0}>0$. Let $\mathrm{g}^{\prime}>0$.

Then $S^{\prime}$ is in $f(C)$ and the minimality of $P_{2}$ and the uniqueness of $\mathbf{c}$ induce $\mathrm{S}^{\prime}=\mathrm{P}_{2}$ and $\mathrm{S}=\mathrm{O}$. Next we treat the case $\mathrm{g}_{1}=\mathrm{g}_{2}=\mathrm{g}_{0}$. Then $\mathrm{h}_{1}<\mathrm{h}_{0}<$ $h_{2}$. Hence $S^{\prime}=\left(0, h_{2}-h_{0}\right)$. Thus $2 \triangle O S^{\prime} Q=b\left(h_{2}-h_{0}\right)$. It contradicts $(10)$.

( In case $\mathrm{g}_{1}>\mathrm{g}_{2}$ ) We make parallelotope OS'P $\mathrm{P}_{1} \mathrm{~S}$. Here the same reasoning works and we get (ii).

We note here the following relation which is equivalent to (ii).

$\mathrm{g}_{1} \mathrm{~h}_{2}-\mathrm{g}_{2} \mathrm{~h}_{1}=1$.

(Proof of (iii)) If $\mathrm{P}_{3} \in \mathrm{f}(\mathrm{B})$, it contradicts the minimality of $\mathrm{b}_{2}$. And also we see $P_{3} \notin f(C)$. Thus we ascertain that $P_{3}$ does not lie on $u_{1}$. Since (b, $\mathrm{w})=1, \mathrm{P}_{3} \in \mathrm{u}_{1}$ means $\mathrm{P}_{3}=(\mathrm{tb}, \mathrm{tw})$ with $\mathrm{t} \in \mathbf{N}$. Thus $\mathrm{g}_{1}+\mathrm{g}_{2}=\mathrm{tb}$ and $h_{1}+h_{2}=t w$. By (11) we have $\left(t b-g_{2}\right) h_{2}-g_{2}\left(t w-h_{2}\right)=t\left(h_{2} b-g_{2} w\right)$ $=1$. Thus $c_{3}=1$, which contadicts (6). The same reasoning works for $\mathrm{u}_{2}$ and we get (iii).

( Proof of (iv)) We put $\mathrm{A}=\left\{(\mathrm{x},-\mathrm{y},-\mathrm{z}): \mathrm{ax}-\mathrm{by}-\mathrm{cz}=0,(\mathrm{x}, \mathrm{y}, \mathrm{z}) \in \mathrm{N}^{3}, \mathrm{y}<\mathrm{b}_{2}, \mathrm{z}<\mathrm{c}_{3}\right\}$. Note that (iii) shows $\mathbf{a} \in \mathrm{A}$. Let two elements $\left(\mathrm{x}_{\mathrm{i}},-\mathrm{y}_{\mathrm{i}},-\mathrm{z}_{\mathrm{i}}\right)(\mathrm{i}=1,2)$ be in A. Here we show that

$$
\mathrm{x}_{1} \neq \mathrm{x}_{2} \text { and } \mathrm{x}_{1}>\mathrm{x}_{2} \text { implies } \mathrm{y}_{1}>\mathrm{y}_{2} \text { and } \mathrm{z}_{1}>\mathrm{z}_{2} \text {. }
$$


Let $\mathrm{x}_{1}, \geqq \mathrm{x}_{2}$ and make the 0 -form $\left(\mathrm{x}_{1}-\mathrm{x}_{2},-\mathrm{y}_{1}+\mathrm{y}_{2},-\mathrm{z}_{1}+\mathrm{z}_{2}\right)=\mathbf{x}$. If $\mathrm{x}_{1}=\mathrm{x}_{2}$, then $(\mathrm{b}, \mathrm{c})=1$ implies $\left|\mathrm{y}_{1}-\mathrm{y}_{2}\right| \geqq c$, which contradicts the property $1 \leqq \mathrm{y}_{\mathrm{i}}<\mathrm{b}_{2}<\mathrm{c}$. Thus we have $\mathrm{x}_{1}>\mathrm{x}_{2}$. Since $\mathbf{x}$ is a 0 -form, at least one of

(13) $-\mathrm{y}_{1}+\mathrm{y}_{2},-\mathrm{z}_{1}+\mathrm{z}_{2}$

is negative. But if exactly one of (13) is negative, it contradicts the minimality of $\mathbf{b}$ or $\mathbf{c}$. Thus we obtain (12).

Next we assume the existence of $\hat{\mathbf{a}}=\left(\hat{\mathrm{a}}_{1},-\hat{\mathrm{a}}_{2},-\hat{\mathrm{a}}_{3}\right)$ in $\mathrm{A}$ for which $\hat{a}_{1}<a_{1}$. By (12), we see that $\mathrm{f}(\hat{\mathbf{a}})$ lies in the parallelotope $\mathrm{OP}_{1} \mathrm{P}_{3} \mathrm{P}_{2}$. It contradicts (11).

Now we put

$$
\begin{aligned}
& \mathrm{V}=\mathrm{V}_{1} \cup \mathrm{V}_{2} \text { with } \\
& \mathrm{V}_{1}=\left\{(\mathrm{y}, \mathrm{z}) \in \mathrm{N}^{2}: \mathrm{y} \leqq \mathrm{b}_{2}, \mathrm{z} \leqq \mathrm{a}_{3}\right\}, \\
& \mathrm{V}_{2}=\left\{(\mathrm{y}, \mathrm{z}) \in \mathrm{N}^{2}: \mathrm{y} \leqq \mathrm{a}_{2}, \mathrm{z} \leqq \mathrm{c}_{3}\right\} .
\end{aligned}
$$

And for $(y, z)$ in $\mathbf{N}^{2}$, we define

$$
\mathrm{H}(\mathrm{y}, \mathrm{z})=\mathrm{by}+\mathrm{cz} .
$$

Lemma 5. (i) $\{\mathrm{H}(\mathrm{y}, \mathrm{z}):(\mathrm{y}, \mathrm{z}) \in \mathrm{V}\}$ makes a complete residue system modulo a.

(ii) Take $\left(\mathrm{y}_{0}, \mathrm{z}_{0}\right) \in \mathrm{V}$. Then $\mathrm{H}\left(\mathrm{y}_{0}, \mathrm{z}_{0}\right)$ is the minimum among

$$
\left\{\mathrm{H}(\mathrm{y}, \mathrm{z}): \mathrm{H}(\mathrm{y}, \mathrm{z}) \equiv \mathrm{H}\left(\mathrm{y}_{0}, \mathrm{z}_{0}\right) \quad(\bmod \mathrm{a}),(\mathrm{y}, \mathrm{z}) \in \mathrm{N}^{2}\right\} .
$$

Proof. We say two lattice points $\left(\mathrm{y}_{\mathrm{i}}, \mathrm{z}_{\mathrm{i}}\right)(\mathrm{i}=1,2)$ to be congruent if $\mathrm{H}\left(\mathrm{y}_{1}, \mathrm{z}_{1}\right) \equiv \mathrm{H}\left(\mathrm{y}_{2}, \mathrm{z}_{2}\right)$ (mod a). We consider the following three translations of lattice points.

$$
\begin{aligned}
& S_{1}(y, z)=\left(y-b_{2}, z+b_{3}\right), S_{2}(y, z)=\left(y+c_{2}, z-c_{3}\right), \\
& S_{3}(y, z)=\left(y-a_{2}, z-a_{3}\right) .
\end{aligned}
$$

As easily seen, these three relations satisfy

$\mathrm{S}_{\mathrm{i}}(\mathrm{y}, \mathrm{z})$ is congruent to $(\mathrm{y}, \mathrm{z})$ and $\mathrm{H}(\mathrm{y}, \mathrm{z})>\mathrm{H}\left(\mathrm{S}_{\mathrm{i}}(\mathrm{y}, \mathrm{z})\right)(1 \leqq \mathrm{i} \leqq 3)$. Hence for a lattice point of $\mathbf{N}^{2}-V$, we obtain a congruent point with a smaller $H$-value by operating a suitable $S_{i}$. Since $H$-value is a positive integer 
for $(y, z) \in \mathbf{N}^{2}$, this process terminates at some point of $\mathrm{V}$.

Next assume that two points $\left(y_{1}, z_{1}\right)$ and $\left(y_{2}, z_{2}\right)$ of $V$ are conguruent. We have

$$
\left(y_{1}-y_{2}\right) b+\left(z_{1}-z_{2}\right) c=x a \text { with } x \in Z \text {. }
$$

Now (6) implies that none of the coefficients of (14) cannot be 0 . Thus we may assume $\mathrm{x}>0$ and there are the following three possibilities.
(A) $\mathrm{y}_{1}>\mathrm{y}_{2}, \mathrm{z}_{1}>\mathrm{z}_{2}$
(B) $y_{1}<y_{2}, z_{1}>z_{2}$
(C) $y_{1}>y_{2}, z_{1}<z_{2}$.

Here (B) or (C) contradicts the minimality of $\mathbf{b}$ or $\mathbf{c}$. And the impossibility of (A) follows from (12) and the minimality of $\mathbf{a}$.

Now we state Theorem 1 which is the main theorem of [1]

Theorem 1. Let $\mathrm{a}, \mathrm{b}$ and $\mathrm{c} \in \mathrm{N}$ and satisy (\#). Notations being as above, we have $\mathrm{F}(\mathrm{a}, \mathrm{b}, \mathrm{c})=\operatorname{Max}\left(\mathrm{H}\left(\mathrm{b}_{2}, \mathrm{a}_{3}\right), \mathrm{H}\left(\mathrm{a}_{2}, \mathrm{c}_{3}\right)\right)$.

Proof. We put $\mathrm{M}=\operatorname{Max} \mathrm{H}(\mathrm{y}, \mathrm{z})$ for $(\mathrm{y}, \mathrm{z}) \in \mathrm{V}$. Then by the convexity of $\mathrm{H}$, we have $\mathrm{M}=\operatorname{Max}\left(\mathrm{H}\left(\mathrm{b}_{2}, \mathrm{a}_{3}\right), \mathrm{H}\left(\mathrm{a}_{2}, \mathrm{c}_{3}\right)\right)$. We show $\mathrm{F}(\mathrm{a}, \mathrm{b}, \mathrm{c})=\mathrm{M}$. First assume $M=x a+y b+z c$ with $(x, y, z) \in \mathbf{N}^{3}$. Then $M-x a=H(y, z)$, which contradicts (ii) of Lemma 5. On the other hand for $n>M$, we can choose $\mathrm{x} \in \mathbf{N}$ so that $\mathrm{n}-\mathrm{xa}=\mathrm{H}\left(\mathrm{y}_{0}, \mathrm{z}_{0}\right)$ with $\left(\mathrm{y}_{0}, \mathrm{z}_{0}\right) \in \mathrm{V}$. Thus $\mathrm{n}=\mathrm{xa}$ $+y_{0} b+z_{0} c$.

\section{Expression of a, b, c and $\mathrm{F}$ with six parameters.}

Lemma 6. Let $\mathbf{b}=\left(b_{1},-b_{2}, b_{3}\right)$ and $\mathbf{c}=\left(c_{1}, c_{2},-c_{3}\right)$ be the vectors determined from $\{\mathrm{a}, \mathrm{b}, \mathrm{c}\}$ with (\#) as in $\$ 2$. Then we have

$$
a=b_{2} c_{3}-b_{3} c_{2}, b=b_{1} c_{3}+b_{3} c_{1}, c=b_{1} c_{2}+b_{2} c_{1} \text {. }
$$

Proof. The assertion of Lemma 5 implies that the cardinality of the lattice points of $\mathrm{V}$ is a. Thus we have the first relation of (15). We note here the symmetric nature of a given in (iv) of Lemma 5. Namely by starting from $\{b, a, c\}$, we obtain 0 -forms $\left(a_{2},-a_{1}, a_{3}\right)$ and $\left(c_{2}, c_{1},-c_{3}\right)$ which play 
a role of $\mathbf{b}$ and $\mathbf{c}$ stated in $\S 2$. Hence we obtain

$$
\mathrm{b}=\mathrm{a}_{1} \mathrm{c}_{3}-\mathrm{a}_{3} \mathrm{c}_{1}=\left(\mathrm{b}_{1}+\mathrm{c}_{1}\right) \mathrm{c}_{3}-\mathrm{c}_{1}\left(\mathrm{c}_{3}-\mathrm{b}_{3}\right)=\mathrm{b}_{1} \mathrm{c}_{3}+\mathrm{c}_{1} \mathrm{~b}_{3} .
$$

The relation (15) for $\mathrm{c}$ follows with a similar reasoning.

As shown in Lemmas 4 and $6, \mathbf{b}=\left(b_{1},-b_{2}, b_{3}\right)$ and $\mathbf{c}=\left(c_{1}, c_{2},-c_{3}\right)$ made from $\{a, b, c\}$ with (\#) satisfies the following ( $($ ) .

(日) $\quad b_{i}, c_{i} \in N, \quad\left(b_{i}, c_{i}\right)=1 \quad(1 \leqq i \leqq 3), b_{2}>c_{2}$ and $c_{3}>b_{3}$.

We show here the $\operatorname{set}\{\mathbf{b}, \mathbf{c}\}$ is characterized by (

Lemma 7. Take $\{a, b, c\}$ with (\#). Let $\hat{\mathbf{b}}=\left(\hat{\mathrm{b}}_{1},-\widehat{\mathrm{b}}_{2}, \widehat{\mathrm{b}}_{3}\right)$ and $\hat{\mathbf{c}}=$ $\left(\hat{\mathrm{c}}_{1}, \hat{\mathrm{c}}_{2},-\hat{\mathrm{c}}_{3}\right)$ satisfy the following $(\hat{\mathrm{G}})$.

(旬) $\hat{b}_{i}, \hat{c}_{i} \in N, \quad\left(\hat{b}_{i}, \hat{c}_{i}\right)=1 \quad(1 \leqq i \leqq 3), \quad \hat{b}_{2}>\hat{c}_{2}, \quad \hat{c}_{3}>\hat{b}_{3}$.

$$
\mathrm{a}=\hat{\mathrm{b}}_{2} \hat{\mathrm{c}}_{3}-\hat{\mathrm{b}}_{3} \hat{\mathrm{c}}_{2}, \mathrm{~b}=\hat{\mathrm{b}}_{1} \hat{\mathrm{c}}_{3}+\widehat{\mathrm{b}}_{3} \hat{\mathrm{c}}_{1}, \mathrm{c}=\hat{\mathrm{b}}_{1} \hat{\mathrm{c}}_{2}+\hat{\mathrm{b}}_{2} \hat{\mathrm{c}}_{1} \text {. }
$$

Then $\widehat{\mathbf{b}}=\mathbf{b}$ and $\hat{\mathbf{c}}=\mathbf{c}$.

Proof. It is an easy calculation to see that $\widehat{\mathbf{b}}$ and $\hat{\mathbf{c}}$ are 0 -forms for $\{a$, b, c $\}$. Thus by (ii) of Lemma 4, they are $\mathbf{Z}$-combinations of $\mathbf{b}$ and $\mathbf{c}$. We put

$$
\left(\begin{array}{ll}
s & t \\
u & v
\end{array}\right)\left(\begin{array}{ccc}
b_{1} & -b_{2} & b_{3} \\
c_{1} & c_{2} & -c_{3}
\end{array}\right)=\left(\begin{array}{ccc}
\widehat{b_{1}} & -\widehat{b_{2}} & \widehat{b_{3}} \\
\widehat{c_{1}} & \widehat{c_{2}} & -\widehat{c_{3}}
\end{array}\right) \text { with } s, t, u, v \in Z \text {. }
$$

Here $\left|\begin{array}{ll}\mathrm{s} & \mathrm{t} \\ \mathrm{u} & \mathrm{v}\end{array}\right|\left|\begin{array}{rr}-\mathrm{b}_{2} & \mathrm{~b}_{3} \\ \mathrm{c}_{2} & -\mathrm{c}_{3}\end{array}\right|=\left|\begin{array}{rr}-\widehat{\mathrm{b}_{2}} & \widehat{\mathrm{b}_{3}} \\ \widehat{\mathrm{c}_{2}} & -\widehat{\mathrm{c}_{3}}\end{array}\right|=\mathrm{a} \quad$ implies the relation

(16) $\mathrm{sv}-\mathrm{tu}=1$.

By ( $(\hat{G})$, we obtain the following eight inequalities.
(A) $\mathrm{sb}_{1}+\mathrm{tc}_{1}>0$
(B) $\mathrm{tc}_{2}<\mathrm{sb}_{2}$
(C) $\mathrm{sb}_{3}>\mathrm{tc}_{3}$
(D) $\mathrm{ub}_{1}+\mathrm{vc}_{1}>0$
(E) $\mathrm{vc}_{2}>\mathrm{ub}_{2}$
(F) $\mathrm{ub}_{3}<\mathrm{vc}_{3}$
(G) $\mathrm{sb}_{2}-\mathrm{tc}_{2}>\mathrm{vc}_{2}-\mathrm{ub}_{2}$
(H) $\mathrm{vc}_{3}-\mathrm{ub}_{3}>\mathrm{sb}_{3}-\mathrm{tc}_{3}$

By (B), $s \leqq 0$ implies $t<0$, which contradicts (A). Thus we have $\mathrm{s}>0$. By a similar way, we have $\mathrm{v}>0$. Thus (16) implies tu $\geqq 0$. We consider separating according the signatures of $t$ and $u$. 
$(\mathrm{t}=0)$ Let $\mathrm{t}=0$. Then (16) implies $\mathrm{s}=\mathrm{v}=1$. By $(\mathrm{G}),(1+\mathrm{u}) \mathrm{b}_{2}>\mathrm{c}_{2}$. Hence $u \geqq 0$. On the other hand (E) and $(G)$ induces $u \leqq 0$. Namely $u=0$. $(\mathrm{u}=0)$ By the same reasoning, we obtain $\mathrm{s}=\mathrm{v}=1$ and $\mathrm{t}=0$. $(t>0, u>0)$ Now $(C)$ and $(\xi)$ imply $s>t$. And (E) and ( $(\mathrm{t})$ induce $v$ $>$ u.

Thus $\mathrm{sv}-\mathrm{tu} \geqq(\mathrm{t}+1)(\mathrm{u}+1)-\mathrm{tu} \geqq 3$, which contradicts (16).

$(\mathrm{t}<0, \mathrm{u}<0)$ We put $-\mathrm{t}=\mathrm{t}^{\prime}$ and $-\mathrm{u}=\mathrm{u}^{\prime}$. From $(G)$ and $(\mathrm{H})$, we get (17)

$$
\left(s-u^{\prime}\right)>\left(v-t^{\prime}\right)\left(c_{2} / b_{2}\right)>\left(s-u^{\prime}\right)\left(b_{3} c_{2} / b_{2} c_{3}\right) \text {. }
$$

By $(a)$, we see $1>b_{3} c_{2} / b_{2} c_{3}>0$. Thus (17) implies $s>u^{\prime}$ and $v>t^{\prime}$. Since $t u=t^{\prime} u^{\prime}$, these inequalities contradict (16).

Thus we see the only possible case is $\mathrm{s}=\mathrm{v}=1$, and $\mathrm{t}=\mathrm{u}=0$.

Remark. From numerically given $\{a, b, c\}$ with (\#), we obtain $b_{i}, c_{i}$ ( $1 \leqq$ $i \leqq 3$ ) by using the Davison's algorithm given in [2]. Strictly speaking, it gives a method to obtain $b_{2}, b_{3}, c_{2}, c_{3}$ and F. As easily seen,

$$
b_{1}=\left(b_{2} b-b_{3} c\right) / a \text { and } c_{1}=\left(c_{3} c-c_{2} b\right) / a \text {. }
$$

Theorem 2. We take six numbers $b_{i}, c_{i}(1 \leqq i \leqq 3)$ which satisfy ( 1$)$. Then $\{a, b, c\}$ given by (15) satisfy (\#) except the condition $(a, b, c)=1$. In case $(\mathrm{a}, \mathrm{b}, \mathrm{c})=1$, we have $\mathrm{F}(\mathrm{a}, \mathrm{b}, \mathrm{c})=\operatorname{Max}\left(\mathrm{F}_{1}, \mathrm{~F}_{2}\right)$ where

$$
\begin{aligned}
& F_{1}=b_{1} b_{2} c_{3}+b_{1} c_{2} c_{3}+c_{1} b_{2} c_{3}-b_{1} c_{2} b_{3}, \\
& F_{2}=b_{1} b_{2} c_{3}+c_{1} b_{2} b_{3}+c_{1} b_{2} c_{3}-c_{1} c_{2} b_{3} .
\end{aligned}
$$

Proof. We assume $(a, b, c)=1$, and show that the set $\{a, b, c\}$ satisfy the other conditions of (\#). Assume $(b, c)>1$, and take a prime $p$ for which $\mathrm{p} \mid(\mathrm{b}, \mathrm{c})$.

(Case 1) If $\mathrm{p} \nmid \mathrm{b}_{1}$, then $\mathrm{p} \mid \mathrm{b}$ implies $\mathrm{c}_{3} \equiv-\widehat{\mathrm{b}}_{1} \mathrm{c}_{1} \mathrm{~b}_{3}(\bmod \mathrm{p})$ with $\hat{\mathrm{b}}_{1}$ for which $\hat{b}_{1} b_{1} \equiv 1(\bmod p)$. And $p \mid c$ implies $c_{2} \equiv-\widehat{b}_{1} b_{2} c_{1}(\bmod p)$. These two relations imply $\mathrm{p} \mid \mathrm{a}$. It contradits $(\mathrm{a}, \mathrm{b}, \mathrm{c})=1$.

(Case 2) If $p \mid b_{1}$, then $\left(b_{1}, c_{1}\right)=1$ and $p \mid b$ imply $p \mid b_{3}$. Similarly $p \mid b_{2}$. Thus we have $p \mid a$.

Hence we see $(b, c)=1$. Similar reasoning works for the other pairs . 
Next we show that a cannot be $\mathbf{N}$-dependent on $\{b, c\}$. Let $a=t b+u c$ with $(t, u) \in \mathbf{N}^{2}$. Substituting this relation to $b_{1} a-b_{2} b+b_{3} c=0$, we have $\left(b_{2}-b_{1} t\right) b=c\left(b_{3}+b_{1} u\right)$. Now $(b, c)=1$ implies $b_{2} \equiv b_{1} t(\bmod c)$. And noting $b_{2}>b_{1} t$, we get a contradiction to (6). We obtain the desired property for the other pairs by a symmetric reasoning.

The other assertions of Theorem follows easily from Lemma 7 and Theorem 1.

\section{Properties of $\mathrm{F} /(\mathrm{abc})^{1 / 2}$}

In [2], the author proved the inequality $\mathrm{F} /(\mathrm{abc})^{1 / 2} \geqq \sqrt{3}$. We put (18) $\theta(a, b, c)=F(a, b, c) /(a b c)^{1 / 2}, \theta_{i}=F_{i} /(a b c)^{1 / 2}(i=1,2)$.

We introduce three parameters (p, $q, r)$ so that

(19) $p\left(b_{1}+c_{1}\right)=b_{1}, \quad q b_{2}=c_{2}, \quad c_{3}(1-r)=b_{3}$.

Now by $(h)$, we see $(p, q, r) \in E$ where

$$
\mathrm{E}=\{(\mathrm{p}, \mathrm{q}, \mathrm{r}): 0<\mathrm{p}<1,0<\mathrm{q}<1,0<\mathrm{r}<1\} .
$$

By Theorem 2, we have

$$
\begin{aligned}
& \theta_{1}(a, b, c)=(1+p q r) / S(p, q, r) \\
& \theta_{2}(a, b, c)=(1+(1-p)(1-q)(1-r)) / S(p, q, r) \\
& \text { where } S(p, q, r)=\{(1-p+p q)(1-q+q r)(1-r+r p)\}^{1 / 2}
\end{aligned}
$$

In this $\S$ we use three expressions $\theta_{i}(a, b, c), \theta_{i}(p, q, r)$ and $\theta_{i}(P)$ where $(\mathrm{a}, \mathrm{b}, \mathrm{c}) \in \mathbf{N}^{3},(\mathrm{p}, \mathrm{q}, \mathrm{r}) \in \mathrm{E}$ and $\mathrm{P}=(\mathrm{p}, \mathrm{q}, \mathrm{r})$ respectively. (We think there is no fear of ambiguity.)

We fix $\mathrm{p}=\alpha$ and let (q, r) run through the following $\mathrm{S}(\alpha)$ :

$$
\mathrm{S}(\alpha)=\{(\mathrm{q}, \mathrm{r}): 0 \leqq \mathrm{q} \leqq 1,0 \leqq \mathrm{r} \leqq 1, \quad \mathrm{p}=\alpha\} .
$$

(We let $\mathrm{S}(\alpha)$ contain the boundary of it for the convenience of our discussion.) We name the four vertices of $S(\alpha)$ as follows.

$$
\mathrm{A}=(0,0), \mathrm{B}=(1,0), \mathrm{C}=(1,1), \mathrm{D}=(0,1) \text {. }
$$

Note that (20) has a symmetry with respect to

$$
(p, q, r) \rightarrow(1-p, 1-q, 1-r) .
$$

Thus we may restrict our research to $\alpha$ which satisfies (21) $0<\alpha \leqq 1 / 2$. 
Fact 1 . We put $\mathrm{L}(\alpha)$ so that

(22) $\mathrm{L}(\alpha)=\{(\mathrm{q}, \mathrm{r}) \in \mathrm{S}(\alpha): \mathrm{r}=(1-\alpha)(1-\mathrm{q}) /(1-\alpha-\mathrm{q}+2 \mathrm{q} \alpha)\}$. Then for $(\mathrm{q}, \mathrm{r}) \in \mathrm{S}(\alpha)$,

$$
\theta_{1}=\theta_{2} \text { if and only if }(\mathrm{q}, \mathrm{r}) \in \mathrm{L}(\alpha) \text {. }
$$

Fact 2. $\mathrm{L}(\alpha)$ is a convex curve in $\mathrm{S}(\alpha)$ which links $\mathrm{B}$ and $\mathrm{D}$. And it divides $\mathrm{S}(\alpha)$ into two domains $\mathrm{D}_{\mathrm{i}}(\alpha)(\mathrm{i}=1,2)$ for which $\theta=\theta_{\mathrm{i}}$ if and only if $(\mathrm{q}, \mathrm{r}) \in \mathrm{D}_{\mathrm{i}}(\alpha)$.

We first study the value of $\theta$ for $(\mathrm{q}, \mathrm{r}) \in \mathrm{L}(\alpha)$.

Fact 3. We obtain

(23) $\theta=(1-\mathrm{q}+\alpha \mathrm{q}) /\{(1-\alpha+\mathrm{q} \alpha)(1-\mathrm{q}) \alpha\}^{1 / 2}$ for (q, $\left.\mathrm{r}\right) \in \mathrm{L}(\alpha)$. Under some calculations, we see that the value of (23) takes its minimum value $2\left(1-\alpha+\alpha^{2}\right)^{1 / 2}$ at the point $\mathrm{T}_{0}(\alpha)$ where

(24) $\mathrm{T}_{0}(\alpha)=\left(\left(1-2 \alpha+2 \alpha^{2}\right) /\left(1-\alpha+2 \alpha^{2}\right),(1-\alpha) /\left(2-3 \alpha+2 \alpha^{2}\right)\right)$. Note that $\theta(\mathrm{D})=1 /\left(\alpha-\alpha^{2}\right)^{1 / 2}$ and $\theta(\mathrm{B})=\infty$.

Next we investigate the values of $\theta$ in $D_{1}(\alpha)$. We see that (21) implies $\partial \theta_{1} / \partial \mathrm{q}>0$ for $(\mathrm{q}, \mathrm{r}) \in \mathrm{D}_{1}$. And $\partial \theta_{1} / \partial \mathrm{r}=0$ at $\mathrm{r}=(2 \mathrm{q}-1) /$ $\mathrm{q}(2-\alpha)$. We put

(25) $\mathrm{T}_{1}(\alpha)=(1 /(1+\alpha),(1-\alpha) /(2-\alpha))$.

Fact 4. $\mathrm{T}_{1}(\alpha) \in \mathrm{L}(\alpha)$. And $\partial \theta_{1} / \partial \mathrm{r}=0$ at $\mathrm{T}_{1}$. For $\mathrm{q}_{0}$ with $\mathrm{q}_{0}>$ $1 /(1+\alpha)$, the point $\mathrm{Q}_{0}=\left(\mathrm{q}_{0},\left(2 \mathrm{q}_{0}-1\right) / \mathrm{q}_{0}(2-\alpha)\right)$ is in $\mathrm{D}_{1}(\alpha)$. At $\mathrm{Q}_{0}$, we have $\partial \theta_{1} / \partial \mathrm{r}=0$ and $\theta\left(\mathrm{Q}_{0}\right)=2\left\{\mathrm{q}_{0} /\left(1-\alpha+\mathrm{q}_{0} \alpha\right)\right\}^{1 / 2}$.

For the behaviour of $\theta$ in $\mathrm{D}_{2}(\alpha)$, we study it by starting from a point of $\mathrm{L}(\alpha)$ and moving along a line $\mathrm{r}=$ const. By calculating $\partial \theta_{2} / \partial \mathrm{q}$, we obtain the following analogous result to Fact 4.

Fact 5. At $\mathrm{T}_{1}(\alpha)$ of (25), $\partial \theta_{2} / \partial \mathrm{q}=0$. And for $\mathrm{r}_{0}<(1-\alpha) /(2-\alpha)$, the point $R_{0}=\left(\left(\alpha+r_{0}-\alpha r_{0}\right) /\left(1-r_{0}\right)(1+\alpha), r_{0}\right)$ is in $D_{2}(\alpha)$. At $R_{0}$ 
,$\partial \theta_{2} / \partial \mathrm{q}=0$ and $\theta_{2}\left(\mathrm{R}_{0}\right)=2\left\{\left(1-\mathrm{r}_{0}\right) /\left(1-\mathrm{r}_{0}+\alpha \mathrm{r}_{0}\right)\right\}^{1 / 2}$. And we put $\mathrm{S}_{0}=\left(\mathrm{q}_{1},\left(\alpha+\mathrm{q}_{1}-\mathrm{q}_{1} \alpha\right) /\left(1-\alpha+\mathrm{q}_{1}-\mathrm{q}_{1} \alpha\right)\right)$ for $\mathrm{q}_{1}<(1-2 \alpha) /(1-\alpha)$.

Then we see $\partial \theta_{2} / \partial \mathrm{r}=0$ at $\mathrm{S}_{0}$, and $\theta_{2}\left(\mathrm{~S}_{0}\right)=2\left\{(1-\alpha) /\left(1-\alpha+\mathrm{q}_{1} \alpha\right)\right\}^{1 / 2}$.

(The role of these three points $Q_{0}, R_{0}$ and $S_{0}$ is illustrated in Figure 2.)

Next we consider the values of $\theta$ at the boundary of $\mathrm{S}(\alpha)$. The values at the four vertices are given by

$$
\begin{aligned}
& \theta(\mathrm{A})=(2-\alpha) /(1-\alpha)^{1 / 2}, \theta(\mathrm{B})=\infty, \theta(\mathrm{C})=(1+\alpha) / \sqrt{\alpha}, \\
& \theta(\mathrm{D})=1 /\left(\alpha-\alpha^{2}\right)^{1 / 2} .
\end{aligned}
$$

Now it is rather an easy task to obtain the following fact.

Fact 6. $\quad(0 \leqq \mathrm{q} \leqq 1, \mathrm{r}=1)$ We have $\theta=\theta_{1}=(1+\mathrm{q} \alpha) /\{\alpha(1-\alpha+$ $\mathrm{q} \alpha)\}^{1 / 2}$. Starting from $\theta(\mathrm{D}), \theta$ increses as $\mathrm{q}$ increases, and reach $\theta(\mathrm{C})$.

$$
(\mathrm{q}=1,0 \leqq \mathrm{r} \leqq 1) \text { In this case, } \theta=\theta_{1}=(1+\alpha \mathrm{r}) /\left\{\mathrm{r}(1-\mathrm{r}+\alpha \mathrm{r})^{1 / 2}\right.
$$

Starting from $\theta(\mathrm{C}), \theta$ decreases with decreasing $r$, and takes the minimum value 2 at $\mathrm{r}=1 /(2-\alpha)$. After that $\theta$ increases and tend to $\infty(=\theta(\mathrm{B}))$.

$$
(\mathrm{q}=0,0 \leqq \mathrm{r} \leqq 1) \quad \theta=\theta_{2}=(2-\alpha-\mathrm{r}+\mathrm{r} \alpha) /\left\{(1-\alpha)(1-\mathrm{r}+\mathrm{r} \alpha)^{1 / 2} .\right.
$$

Starting from $\theta(\mathrm{A}), \theta$ decreses and take the minimum value 2 at $\mathrm{r}=\alpha /$ $(1-\alpha)$. After that $\theta$ increases to $\theta(\mathrm{D})$.

$$
(0 \leqq \mathrm{q} \leqq 1, \mathrm{r}=0) \quad \theta=\theta_{2}=(2-\alpha-\mathrm{q}+\mathrm{q} \alpha) /\{(1-\mathrm{q})(1-\alpha+\mathrm{q} \alpha)\}^{1 / 2} .
$$

Starting from $\theta(\mathrm{A}), \theta$ decreases and take the minimum value 2 at $\mathrm{q}=\alpha /$ $(1+\alpha)$. After that $\theta$ increses to $\infty$.

Collecting above facts we see first that the minimum value of $\theta$ in $S(\alpha)$ is $2\left(1-\alpha+\alpha^{2}\right)^{1 / 2}=\theta\left(\mathrm{T}_{0}(\alpha)\right)$. Thus the minimum value of $\theta$ in $\mathrm{E}$ is $\sqrt{3}$ taken at $(1 / 2,1 / 2,1 / 2)$. But strictly speaking, $\mathrm{p}=\mathrm{q}=\mathrm{r}=1 / 2$ induces $\mathrm{a}=\mathrm{b}=\mathrm{c}=3$, and it contradicts (\#). Thus we obtain the inequality $\theta(\mathrm{a}, \mathrm{b}, \mathrm{c})>\sqrt{3}$ for $\{\mathrm{a}, \mathrm{b}, \mathrm{c}\}$ with (\#). 


\section{Curves $\mathbf{C}(\beta)$}

To visualize the nature of $\theta$ in $\mathrm{S}(\alpha)$, we consider the curve

$$
\mathrm{C}(\beta)=\{(\mathrm{q}, \mathrm{r}) \in \mathrm{S}(\alpha): \theta(\alpha, \mathrm{q}, \mathrm{r})=\beta\} \text { for } \beta \geqq 2\left(1-\alpha+\alpha^{2}\right)^{1 / 2} .
$$

The shape of $\mathrm{C}(\beta)$ in $\mathrm{S}(\alpha)$ varies according to the values of $\beta$. Here we give Figure 2 which illustrates curves $\mathrm{C}(\beta)$ for $\alpha=1 / 3$ and several $\beta$ 's. (We think it may aid in understanding our discussion.)

(i) $\mathrm{C}(\beta)=\mathrm{T}_{0}$ for $\beta=2\left(1-\alpha+\alpha^{2}\right)^{1 / 2}$. As $\beta$ increases from that, $\mathrm{C}(\beta)$ makes a curve which encircles $T_{0}$. On the curve, some of $Q_{0}, R_{0}$ and $S_{0}$ appear as shown in Figure 2.

(ii) As indicated in Fact 6 , the first critical phenomenon appears at $\beta=2$. The curve $\mathrm{C}(2)$ makes a closed curve which contains three points $(0, \alpha /(1-$ $\alpha))=\mathrm{S}_{0},(\alpha /(1+\alpha), 0)=\mathrm{R}_{0}$ and $(1,1 /(2-\alpha))=\mathrm{Q}_{0}$ on the boundary of $\mathrm{S}(\alpha)$. (Figure 3 illustrates the curves $\mathrm{C}(2)$ for $\alpha=1 / 2,1 / 4$ and $1 / 10$.)

(iii) As $\beta$ exceeds 2 , the curve $C(\beta)$ splits to 3 (or less) curves. We name the curves as shown in Figure 4. The cardinality and shape of $\mathrm{C}_{\mathrm{i}}(\beta)$ depends on the order of magnitude of the four numbers $\theta(A), \theta(C), \theta(D)$ and $\beta$.

( The behaviour of $\mathrm{C}_{1}(\beta)$ )

For $\beta$ with $2<\beta<\theta(\mathrm{A}), \mathrm{C}_{1}(\beta)$ is a curve which links the following two

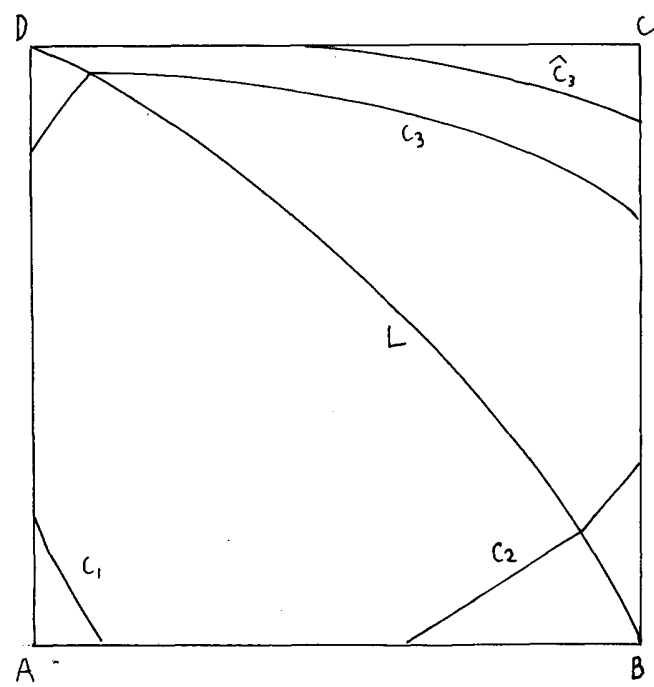

Figure 4. 


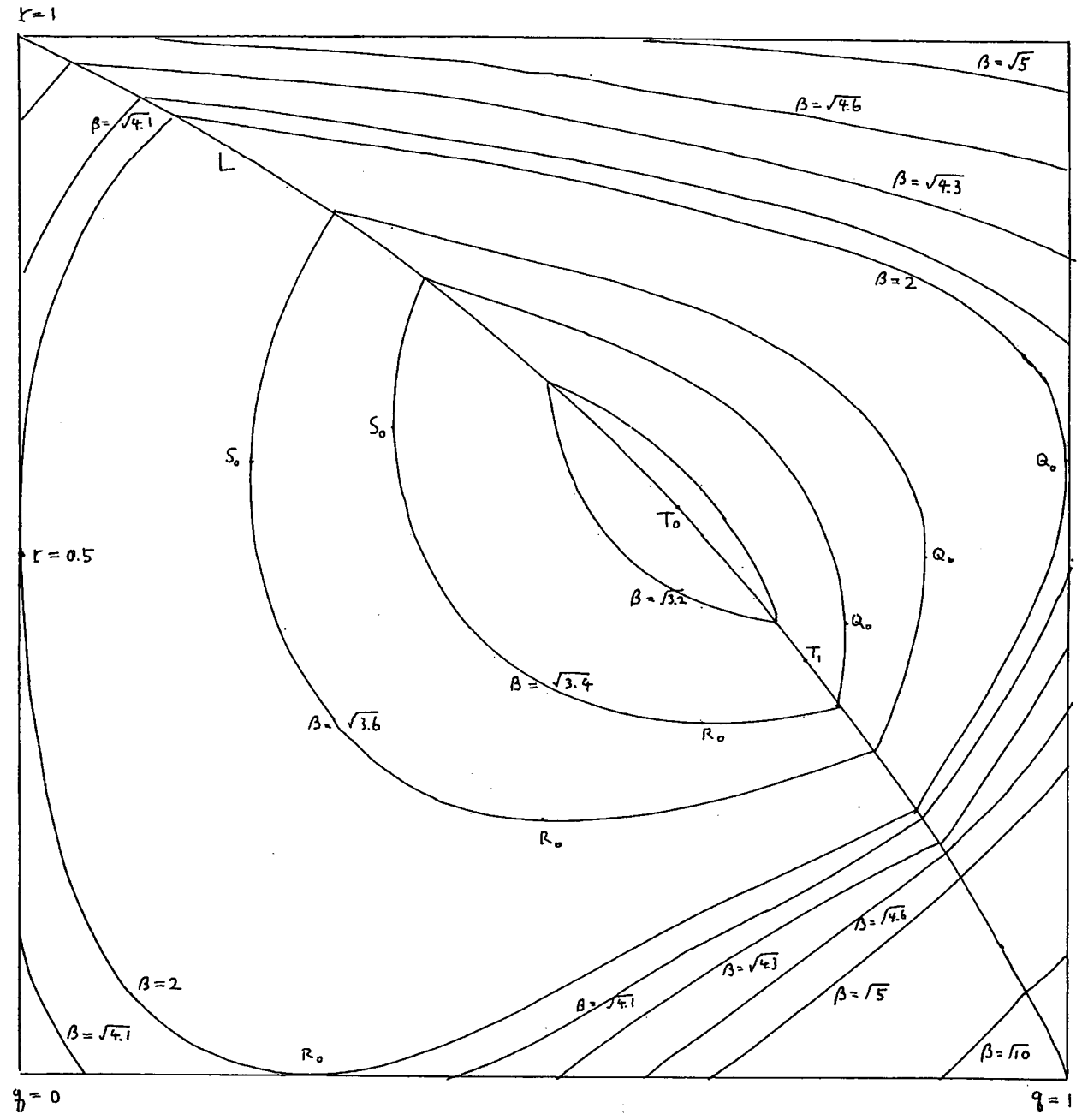

Figure 2.
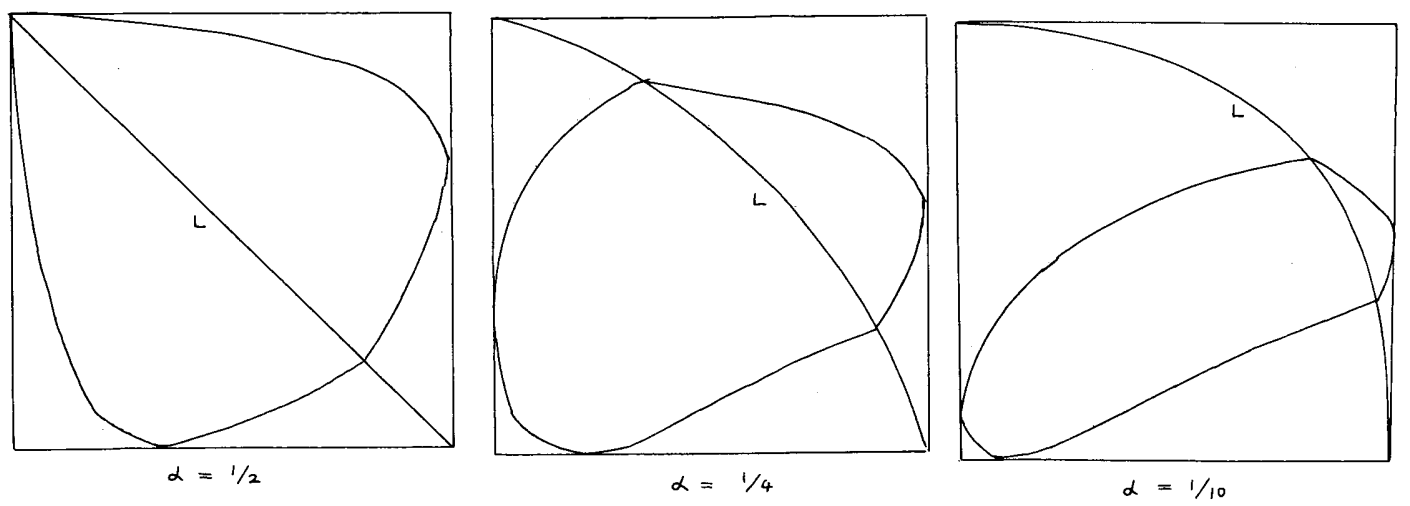

Figure 3. 
points :

$$
\left(0, \frac{2(2-\alpha)-\beta^{2}(1-\alpha)-(1-\alpha) \beta \sqrt{\beta^{2}-4}}{2(1-\alpha)}\right),\left(\frac{2(2-\alpha)(1-\alpha)+(2 \alpha-1) \beta^{2}-\beta \sqrt{\beta^{2}-4}}{2\left((1-\alpha)^{2}+\alpha \beta^{2}\right)}, 0\right) .
$$

For $\beta>\theta(\mathrm{A}), \mathrm{C}_{1}(\beta)=\phi$.

( The behaviour of $\mathrm{C}_{2}(\beta)$ )

For $\beta$ with $2<\beta, C_{2}(\beta)$ is a curves which links the following two points :

$$
\left(\frac{2(2-\alpha)(1-\alpha)+(2 \alpha-1) \beta^{2}+\beta \sqrt{\beta^{2}-4}}{2\left((1-\alpha)^{2}+\alpha \beta^{2}\right)}, 0\right),\left(1, \frac{\left(\beta^{2}-2 \alpha\right)-\beta \sqrt{\beta^{2}-4}}{2\left(\alpha^{2}+(1-\alpha) \beta^{2}\right)}\right) .
$$

And it tends to $\mathrm{B}$ as $\beta \rightarrow \infty$.

( The behaviour of $\mathrm{C}_{3}(\beta)$ )

For $\beta$ with $2<\beta<\theta(D), C_{3}(\beta)$ is a curve as shown in Figure 4, which links the following two points:

$$
\left(0, \frac{2(2-\alpha)-\beta^{2}(1-\alpha)+(1-\alpha) \beta \sqrt{\beta^{2}-4}}{2(1-\alpha)}\right),\left(1, \frac{\left(\beta^{2}-2 \alpha\right)+\beta \sqrt{\beta^{2}-4}}{2\left(\alpha^{2}+(1-\alpha) \beta^{2}\right)}\right) .
$$

( The behabiour of $\hat{\mathrm{c}}_{3}(\beta)$ )

For $\beta$ with $\theta(\mathrm{D})<\beta<\theta(\mathrm{C})$, the curve of type $\hat{\mathrm{c}}_{3}(\beta)$ appears, which links the following two points :

$$
\left(\frac{\alpha \beta^{2}-2+\alpha \beta \sqrt{\beta^{2}-4}}{2 \alpha}, 1\right),\left(1, \frac{\left(\beta^{2}-2 \alpha\right)+\beta \sqrt{\beta^{2}-4}}{2\left(\alpha^{2}+(1-\alpha) \beta^{2}\right)}\right) .
$$

And for $\beta$ with $\beta>\theta(\mathrm{C})$, this curve disappears.

Fact 7. As shown above, for $\beta>(1+\alpha) / \sqrt{\alpha}$, there appears $C_{2}(\beta)$ only. It means that the value of $\theta$ remains, as anticipated by the author of [2], in a reasonable zone for most of $\{a, b, c\}$ with (\#). But we failed answering the conjectures stated in [2]. (We need more precise knowledge of the distribution of $(p, q, r)$ of $\{a, b, c\}$ with $\operatorname{Max}(a, b, c)<n$ and $(a, b, c)$ $=1$.) 


\section{References}

[1] A. Brauer - E. Shockley, On a problem of Frobenius, J. Reine Angew. Math. 211 (1962), 215-220.

[2] J. L. Davison, On the linear diophantine problem of Frobenius, J. Number Theory 48 (1994), 353-363.

[3] P. Erdös - R. L. Graham, Old and new problems and results in combinatorial number theory, Geneve (1980).

[4] S. M. Johnson, A linear diophantine problem, Canad. J. Math. 12 (1960), 390-398. 